\title{
Langmuir Probe Measurements in the Discharge Channel of a 6-kW Hall Thruster
}

\author{
Bryan M. Reid ${ }^{1}$ and Alec D. Gallimore ${ }^{2}$ \\ University of Michigan, Ann Arbor, MI 48109
}

\begin{abstract}
In an effort to understand the role of neutral flow dynamics in the operation of Hall thrusters, a cylindrical Langmuir probe was used to measure the electron temperature, floating potential, and ion number density in the discharge channel of a 6-kW Hall thruster operating at $300 \mathrm{~V}$ and anode flow rates of 10,20 , and $30 \mathrm{mg} / \mathrm{s}$. To isolate the effect of propellant flow rate, the cathode flow fraction and magnetic field topology were held constant while varying magnetic field strength to minimize discharge current while maximizing thrust. The probe was inserted and removed from the discharge channel by a high-speed positioning system at nine radial locations. The peak ion density calculated by the thin sheath analysis technique was typically upstream of the peak electron temperature location by $3-5 \%$ of the channel length. The peak ion density calculated by the orbitalmotion limited analysis technique coincided with the peak electron temperature location. The peak electron temperature dropped by approximately $5 \mathrm{eV}$ and moved downstream by $3-5 \%$ of the channel length for each addition of $10 \mathrm{mg} / \mathrm{s}$. The electron cooling was attributed to increased electron-neutral collisions. The results indicate a strong dependence between neutral flow rate and the peak plasma property magnitude and location.
\end{abstract}

\section{Nomenclature}

$\begin{array}{lll}A_{p} & =\text { probe area } \\ A_{s} & = & \text { sheath area } \\ b & = & \text { discharge channel width } \\ B & = & \text { magnetic field, } \mathrm{G} \\ C & = & \text { capacitance, } \mathrm{F} \\ e & = & \text { electron charge, } \mathrm{C} \\ I_{\text {cap }} & = & \text { capacitive current, } \mathrm{A} \\ I_{\text {sat }} & = & \text { ion saturation current } \\ k_{B} & = & \text { Boltzmann's constant, } \mathrm{J} / \mathrm{K} \\ L_{c} & = & \text { discharge channel length } \\ m_{e} & = & \text { electron mass, kg } \\ M_{i} & = & \text { ion mass, kg } \\ n_{e} & = & \text { electron number density, } \mathrm{m}^{-3} \\ n_{i} & = & \text { ion number density, } \mathrm{m}^{-3} \\ n_{i, O M L} & =\text { OML ion number density, } \mathrm{m}^{-3} \\ n_{i, t h i n} & =\text { thin sheath ion number density, } \mathrm{m}^{-3} \\ P_{o} & =\text { pressure within discharge channel, torr } \\ T_{e} & =\text { electron temperature, eV } \\ V_{f} & =\text { floating potential, } \mathrm{V} \\ V_{p} & =\text { plasma potential, } \mathrm{V} \\ Z & =\text { axial location, measured from anode } \\ \lambda_{D} & =\text { Debye length, cm }\end{array}$

\footnotetext{
${ }^{1}$ Ph. D. Candidate, Plasmadynamics and Electric Propulsion Laboratory, reidb@umich.edu, and AIAA student member.

2 Arthur F. Thurnau Professor of Aerospace Engineering and Director of the Plasmadynamics and Electric Propulsion Laboratory, alec.gallimore@umich.edu, and AIAA senior member.
} 


\section{Introduction}

$\mathrm{H}$ ALL thrusters have become an integral part of the satellite propulsion architecture. Identifying the ability of Hall thrusters to operate beyond their nominal design points is important for the future viability of the technology. The Hall thruster simulation community is also interested in the behavior across a wide range of operating conditions, using experimental observations to validate and improve existing modeling capability. To understand how Hall thrusters operate at off-nominal conditions, the location, size, and intensity of the ionization and acceleration regions must determined. An excellent method of determining these plasma properties is with electrostatic probe measurements inside the discharge channel.

Langmuir probes are an excellent probe for measuring the electron temperature and ion density in a broad range of plasmas. Previous studies have shown the ability of these probes to operate and survive in the harsh environment that exists in the discharge channel of a Hall thruster [1,2]. To isolate the effect of neutral flow rate, the magnetic field shape, cathode flow fraction, and discharge voltage were kept constant while varying anode flow rate. The magnetic field strength was optimized by minimizing the discharge current while maximizing the measured thrust. The thruster used in this experiment was designed for nominal operation at $6 \mathrm{~kW}(300 \mathrm{~V}$ at $20 \mathrm{mg} / \mathrm{s})$, but during this study it was operated at discharge powers ranging from approximately 3 to $10 \mathrm{~kW}$, corresponding to $300 \mathrm{~V}$ at 10 , 20 , and $30 \mathrm{mg} / \mathrm{s}$.

The experimental apparatus used in this study are covered along with a brief theory of probe operation. Results are shown for floating potential, electron temperature, and ion density throughout the measurement domain. The difference between thin sheath and Orbital Motion Limited (OML) probe operation are discussed, with OML appearing to be more reliable. The discussion section considers possible causes for the electron temperature cooling with increased mass flow rate, and the chronic over prediction of ion number density by the Langmuir probe.

\section{Experimental Apparatus}

\section{A. Vacuum Facility}

Experiments were performed in the Large Vacuum Test Facility (LVTF) at the University of Michigan Plasmadynamics and Electric Propulsion Laboratory (PEPL). The LVTF is a 6-meter-diameter, 9-meter-long, cylindrical, stainless steel vacuum chamber. Pumping is provided by seven single-stage CVI model TM-1200 cryopumps and liquid nitrogen shrouds, with a nominal pumping speed of $240,000 \mathrm{l} / \mathrm{s}$ on xenon. Facility pressure was monitored by two hot-cathode ionization gauges, and base pressure was approximately $2.3 \times 10^{-7}$ torr. The facility pressure during thruster operation at $22 \mathrm{mg} / \mathrm{s}$ total xenon flow rate was approximately $1.3 \times 10^{-5}$ torr, corrected for xenon.

\section{B. Hall Thruster}

Experiments were performed using a $6-\mathrm{kW}$ laboratory model Hall thruster that has an approximate throttling range of $100-600 \mathrm{mN}$ and $1000-3000 \mathrm{~s}$ specific impulse [3-6]. The thruster was equipped with a center-mounted $\mathrm{LaB}_{6}$ hollow cathode that was operated at $7 \%$ of the anode mass flow rate. Research-grade xenon propellant ( $99.999 \%$ pure) was supplied to the anode and cathode by separate commercially-available flow meters and controllers, having an accuracy of $\pm 1 \%$ of full scale. The system was calibrated using a constant volume method including the effects of compressibility [7]. The thruster discharge was sustained by a $100 \mathrm{~kW}$ power supply that provided a maximum output of $1000 \mathrm{~V}$ at $100 \mathrm{~A}$. The thruster was positioned so that it was elevated to chamber centerline, allowing the plume to expand for approximately four meters along the chamber axis.

\section{High-speed Positioning System}

The probe was inserted and removed from the thruster discharge channel using the HARP at PEPL. The HARP has an acceleration and velocity capability of approximately $70 \mathrm{~m} / \mathrm{s}^{2}(7 \mathrm{~g}$ 's) and $2.5 \mathrm{~m} / \mathrm{s}$, respectively [8]. For this experiment, the HARP was operated at $0.75 \mathrm{~m} / \mathrm{s}$, resulting in a residence time within the discharge channel of less than $120 \mathrm{~ms}$.

To reduce the effects of vacuum chamber compression during initial evacuation, the HARP and thruster translation stage were connected by a rigid steel support structure. The HARP was fixed to the support structure downstream of the thruster to dampen oscillations that are produced by the actuation of the probe arm. The thruster was mounted to a $1.5-\mathrm{m}$-long translation stage that adjusted the radial location of the probe within the discharge channel. 

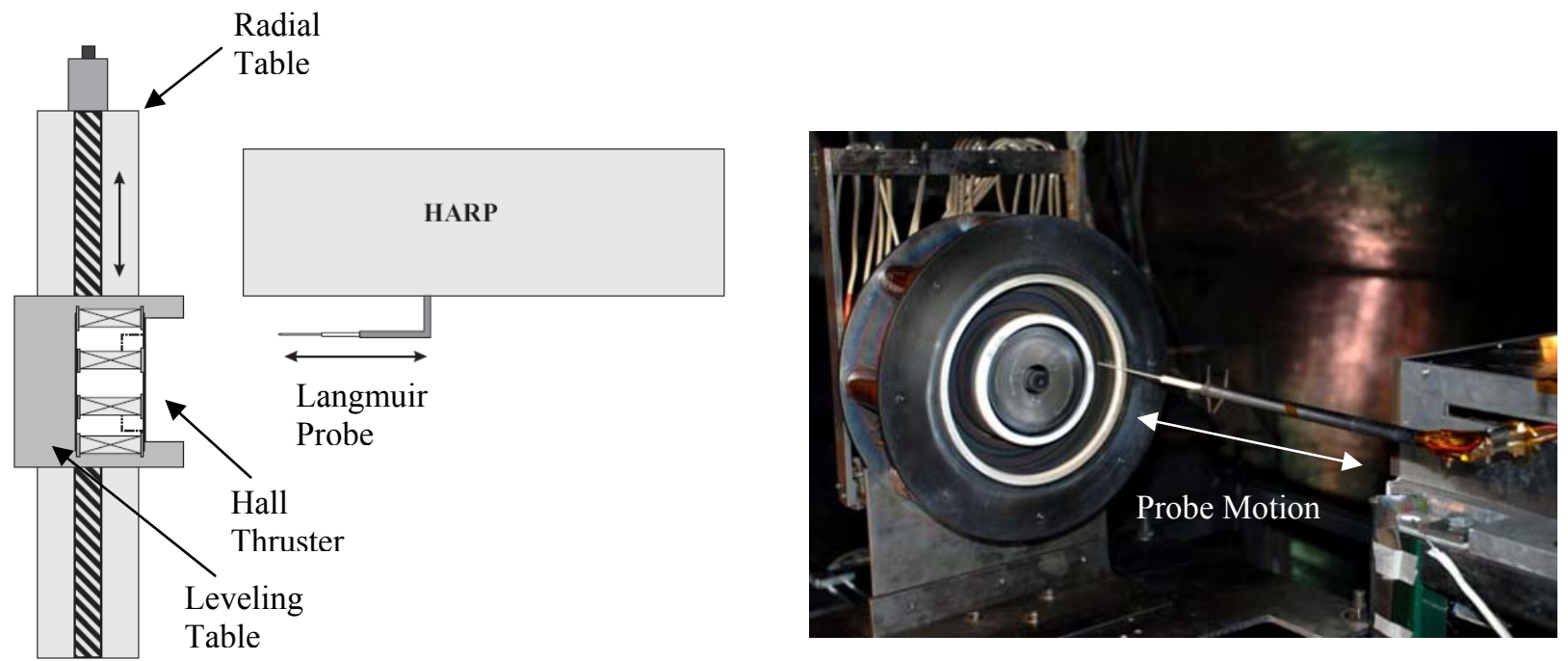

Figure 1. Schematic of thruster and probe positioning systems, and photograph of probe insertion into thruster discharge channel.

\section{Cylindrical Langmuir Probe}

The cylindrical Langmuir probe has significant heritage for measuring the plasma properties in the discharge channel of Hall thrusters. The single Langmuir probe implemented in this experiment was based on the methodology outlined in Refs. [1, 2].

\section{Probe Theory and Analysis}

The Langmuir probe is a widely used electrostatic device that provides a comprehensive set of plasma parameters with a single diagnostic technique. A single electrode is exposed to the plasma and subjected to a range of applied potentials. The plasma response to the probe voltage is measured by the collected current, resulting in a current-voltage (I-V) characteristic that can be used to extract the plasma potential, floating potential, electron temperature, and plasma density. Although the probe construction and implementation are straightforward, the interpretation of the I-V characteristic is complicated by several effects including collisions, magnetic field effects, anisotropy of the Electron Energy Distribution Function (EEDF), end effects, sheath expansion, and thermionic emission [1, 2, 9-11].

The electron mean free path to probe radius was typically greater than one, placing the probe operation primarily in the collisionless regime. The magnetic field effects were determined to be small for these measurements since the probe was perpendicular to the primarily radial magnetic field lines and the electron gyroradius was 6-10 times greater than the probe radius. The error in the electron temperature measurement due to the EEDF anisotropy was expected to be small since B/Po ranged from $1-4 \times 10^{4} \mathrm{G} /$ torr, well below the $2.5 \times 10^{6} \mathrm{G} /$ torr limit recommended in the work of Aikawa [12]. The end effects were accounted for by determining the flux of ions to the tip of the probe. For this calculation, the ion velocity was calculated from plasma potential measurements [13], and the density was updated and iterated until convergence of the ion density was achieved. Similarly, the sheath expansion effects were accounted for in the thin sheath analysis by calculating the sheath size, updating the collection area, and recalculating the ion density until convergence was achieved. The combined corrections due to sheath size and end effects ranged from 30 to $70 \%$ depending on axial location, and the tip correction was typically an order of magnitude less than the sheath size correction.

Each Langmuir probe I-V characteristic was analyzed by an automated script. The script divided each axial probe injection into individual I-V traces based on the probe voltage. The script then located the floating potential by finding the location where the probe current crossed zero. Next, the ion saturation current was calculated based on the mean of all points from 5 to $50 \mathrm{~V}$ below the floating potential. The ion number density was calculated from the ion saturation current using thin sheath [14]

$$
n_{i, \text { thin }}=\frac{I_{i, \text { sat }}}{0.61 A_{s} e} \sqrt{\frac{M_{i}}{k_{B} T_{e}}},
$$


and OML theory $[14,15]$

$$
n_{i, O M L}=\frac{1}{A_{p}} \sqrt{\frac{2 \pi M_{i}}{1.27 e^{3}}\left(\frac{d\left(I_{i}\right)^{2}}{d V}\right)} .
$$

The thin sheath density calculations were corrected for the probe sheath size, and end effects. Finally, the electron temperature was calculated based on the inverse slope of the electron-retarding region. The boundary of the electron-retarding region was determined by taking several points on either side of the location of maximum slope of the I-V curve.

\section{Probe Design}

The Langmuir probe was used to measure the plasma properties in the thruster discharge channel from approximately 3 to $10 \mathrm{~kW}$. As the discharge power increases, the heat load to the probe increases, ultimately leading to probe failure when the ceramic surface temperature reaches a significant fraction of its melting temperature. This critical power limit was reached at $6 \mathrm{~kW}(300 \mathrm{~V}, 20 \mathrm{mg} / \mathrm{s})$ for an alumina probe body based on the design introduced in Ref. [1]. To alleviate the probe failure mechanism associated with elevated thruster discharge power, the portion of the probe that entered the discharge channel was covered with a boron nitride shroud, described in detail in Ref. [13].

The Langmuir probe was constructed using three major components for the body; a 1.5-mm-diameter, doublebore, alumina tube, telescoped inside a 6.4-mm-diameter alumina tube, capped by a graduated boron nitride shroud as shown in Figure 2. The boron nitride shroud was split into three sections with diameters of 3, 5, and $6.4 \mathrm{~mm}$, each of which was 35,8 , and $8 \mathrm{~mm}$ long, respectively. The probe tip was created by a $0.25 \mathrm{~mm}$-diameter tungsten wire that extended beyond the alumina tube by $2 \mathrm{~mm}$.

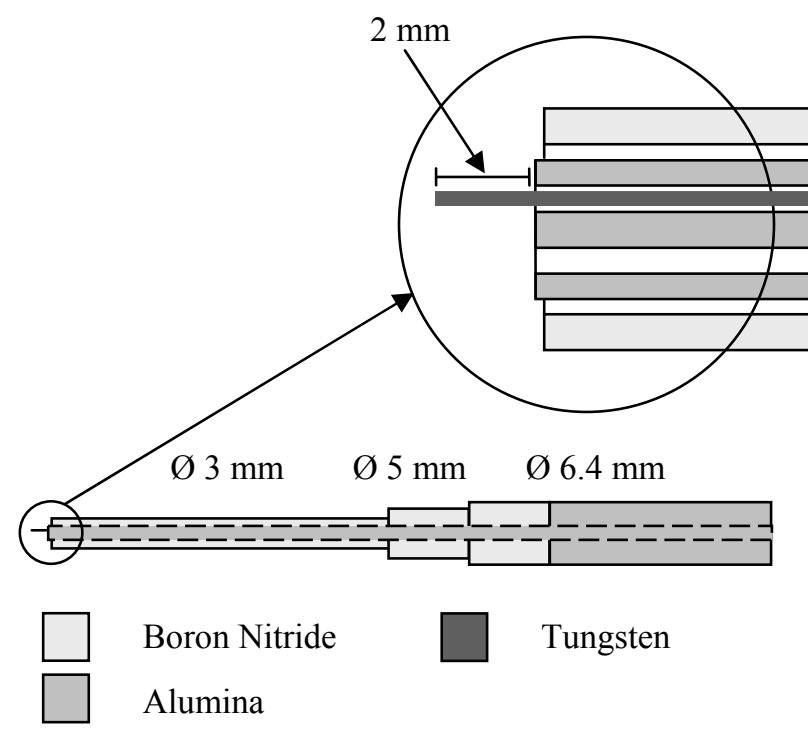

Figure 2. Schematic of Langmuir probe construction (not to scale).

\section{Probe Operation}

Following the work of Linnell [2], continuous I-V traces were achieved for the single Langmuir probe by varying the probe bias using a $380 \mathrm{~Hz}$ triangle wave. As the probe was injected into the thruster, the floating potential (and plasma potential) increased by several hundred volts. In order to capture measurements in the ion saturation and electron retarding regimes of the I-V trace, the probe voltage sweep must oscillate around the floating potential. To satisfy this requirement, the floating potential was measured on channel centerline with an unbiased probe and the profile was sent to a programmable waveform generator. The floating potential profile was then summed with a triangle wave and sent to the input of a bipolar power supply, which amplified the signal to produce the probe bias shown in Figure 3. This method reduced the need for multiple pulses as implemented by Linnell [2], however large differences between the floating and plasma potentials near the peak electron temperature location can require two pulses to capture the ion saturation and a significant portion of the electron retarding regime of the I- 
$\mathrm{V}$ curve. This incremental improvement in the probe bias method reduced data collection time, increased probe lifetime, and increased the ease of data reduction and post-processing.

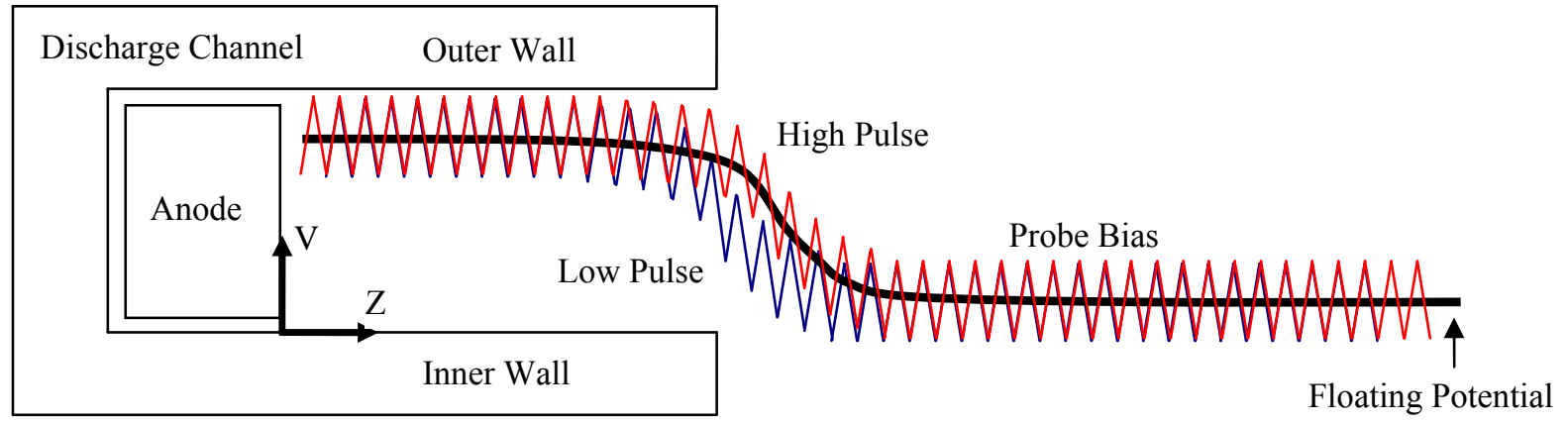

Figure 3. Schematic of Langmuir probe voltage characteristic during injection into the discharge channel.

To minimize thruster perturbations, the probe size should be minimized and the HARP should be operated near its upper velocity limit to decrease the probe residence time. However, increasing the HARP velocity directly increases the necessary probe bias oscillation frequency, which increases the effect due to line capacitance. The line capacitance during this experiment was estimated at $500 \mathrm{pF}$ by monitoring the capacitive current drawn during probe bias oscillation with no plasma. A typical line capacitance calibration is shown in Figure 4, closely matching the theoretical trend where the capacitive current $\left(I_{c a p}\right)$ follows

$$
I_{\text {cap }}=C \frac{d V}{d t}
$$

where $C$ is the line capacitance, and $d V / d t$ is the time derivative of the probe voltage. More than $90 \%$ of the total line capacitance was found to be due to the cable length from the HARP carriage to the probe tip, where the signal wire has a small physical separation from electrical ground. This near-probe capacitance was unavoidable, and prevented all attempts to further reduce line capacitance. The competing factors of thruster perturbation and line capacitance are what led to the selection of HARP velocity of $0.75 \mathrm{~m} / \mathrm{s}$ and triangle wave oscillation frequency of $380 \mathrm{~Hz}$.

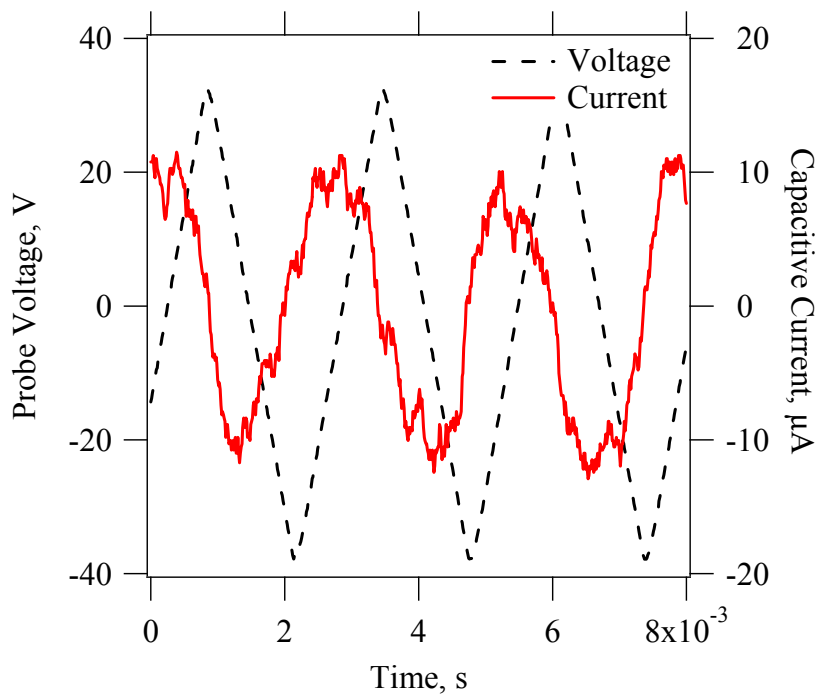

Figure 4. Capacitive current caused by line capacitance due to the probe voltage oscillation.

To prevent excessive heating of the tungsten electrode that can lead to thermionic emission of electrons, the probe bias was not allowed to go more than $100 \mathrm{~V}$ on either side of the floating potential. In addition, the probe was allowed to cool for 15 seconds between each probe injection. If the probe was heated to the point of thermionic emission, the measured current would be offset towards ion saturation. 


\section{Data Acquisition and Probe Measurement Circuit}

The data acquisition (DAQ) system recorded the probe position, probe voltage, probe current, thruster discharge current, and cathode potential at $83 \mathrm{kHz}$ per channel. The measurement frequency combined with the voltage oscillation frequency resulted in approximately 100 points per I-V trace. The limited measurement frequency of the DAQ contributed to the decision to decrease the HARP velocity and voltage oscillation frequency.

The Langmuir probe measurement I-V traces were measured with separate voltage and current measurement circuits. The voltage measurement circuit was composed of two high-impedance thin-film resistors, and the voltage drop across the minor resistor to ground was measured with a voltage following operational amplifier with isolated inputs (shown in gray). The current measurement circuit was composed of a single $100 \Omega$ thin-film resistor placed in series with the probe so that the voltage drop could be measured with an operational amplifier. The operational amplifiers were rated for a minimum bandwidth of $20 \mathrm{kHz}$, well above the $380 \mathrm{~Hz}$ sweep frequency, making them capable of measuring fluctuations resulting from the breathing mode discharge oscillation (see Section II.D.7). The current measuring circuit had a pair of blocking diodes in parallel with the resistor to protect the amplifier in the event of a large spike of current from the plasma. A schematic of the probe bias and measurement circuits are shown in Figure 5.

The voltage and current measurement circuits were enclosed in a grounded case and located inside the chamber to reduce line losses, as shown in Figure 5. The output signal was connected to the DAQ by $50 \Omega$ BNC cables and feed throughs. The voltage and current measurements circuits were calibrated at DC, displaying excellent linearity. The dynamic response was then characterized, displaying a similar response to the one shown in Figure 4. The circuit and bipolar power supply displayed excellent linearity and immeasurable attenuation up to $2 \mathrm{kHz}$, well above the required operation frequency of $380 \mathrm{~Hz}$.

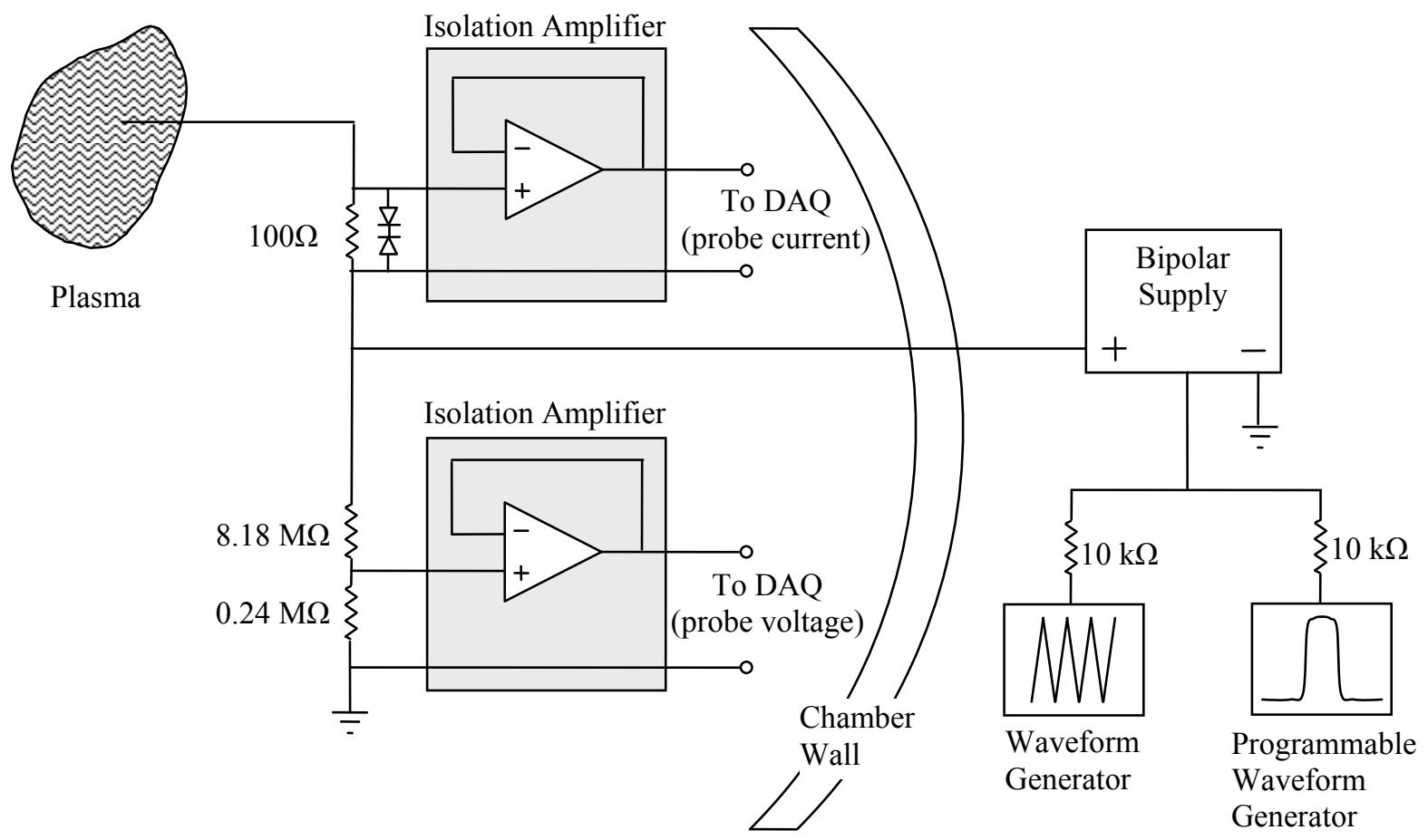

Figure 5. Schematic of Langmuir probe measurement and bias circuits.

\section{Measurement Domain}

The measurement domain was normalized by the channel length, Lc, and channel width, $b$. The anode was located at $0 \% \mathrm{Lc}$, the channel exit was $100 \% \mathrm{Lc}$, the inner wall was located at $0 \% \mathrm{~b}$, and the outer wall was located at $100 \%$ b. Data were taken at nine radial locations spaced $8 \%$ of the channel width apart, as shown in Figure 6. Since the Langmuir probe I-V traces were sampled every $2.5 \%$ of the channel length, the results were considered time-averaged; hence, unable to resolve variations in the plasma properties due to high-frequency oscillations $\left(10^{4}\right.$ $\mathrm{Hz}$ ) that are characteristic of Hall thruster discharges. 


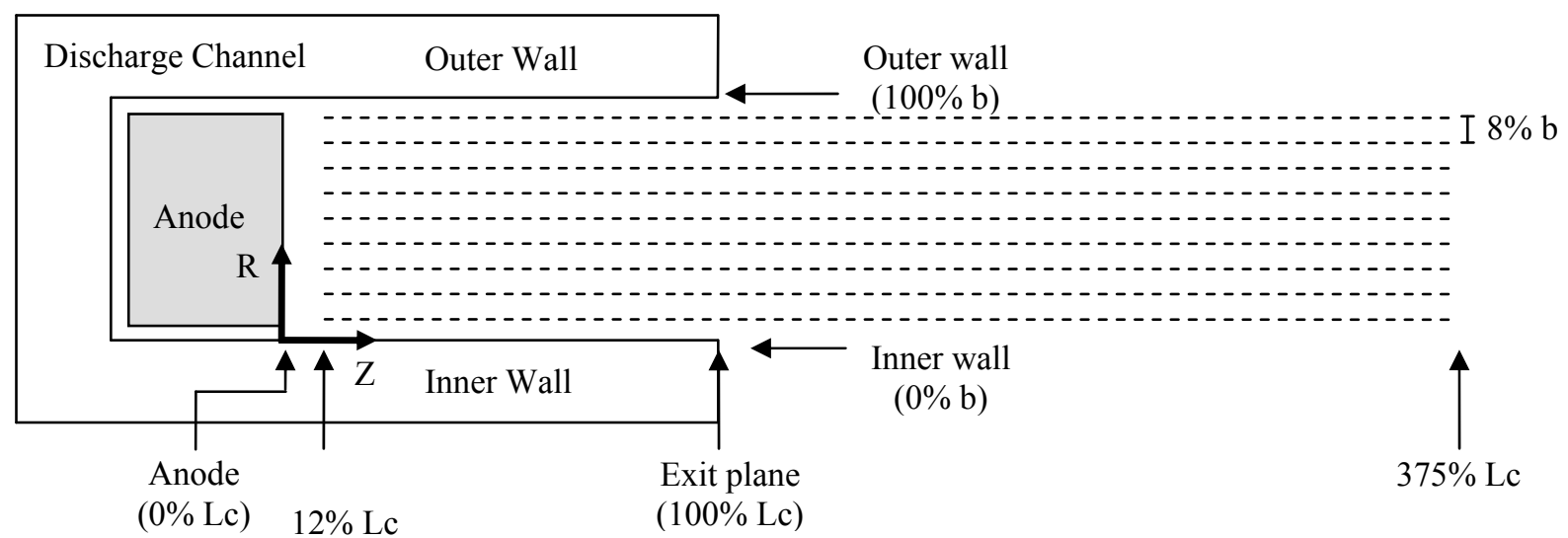

Figure 6. Schematic of measurement domain (not to scale).

\section{Probe-Induced Thruster Perturbations}

Probe-induced thruster perturbations were characterized by examining the discharge current and cathode potential during probe insertion and removal from the thruster channel. The probe position, discharge voltage, and discharge current are shown in Figure 7 for $300 \mathrm{~V}, 10 \mathrm{mg} / \mathrm{s}$. Nominal discharge current oscillations were about $40 \%$, reaching a maximum between $50-60 \%$ as the probe was inserted. The data in Figure 7 are representative of the probe-induced perturbation at all operating conditions, and they remained below $20 \%$, an acceptable value that is consistent with previous work $[1,2,16]$.

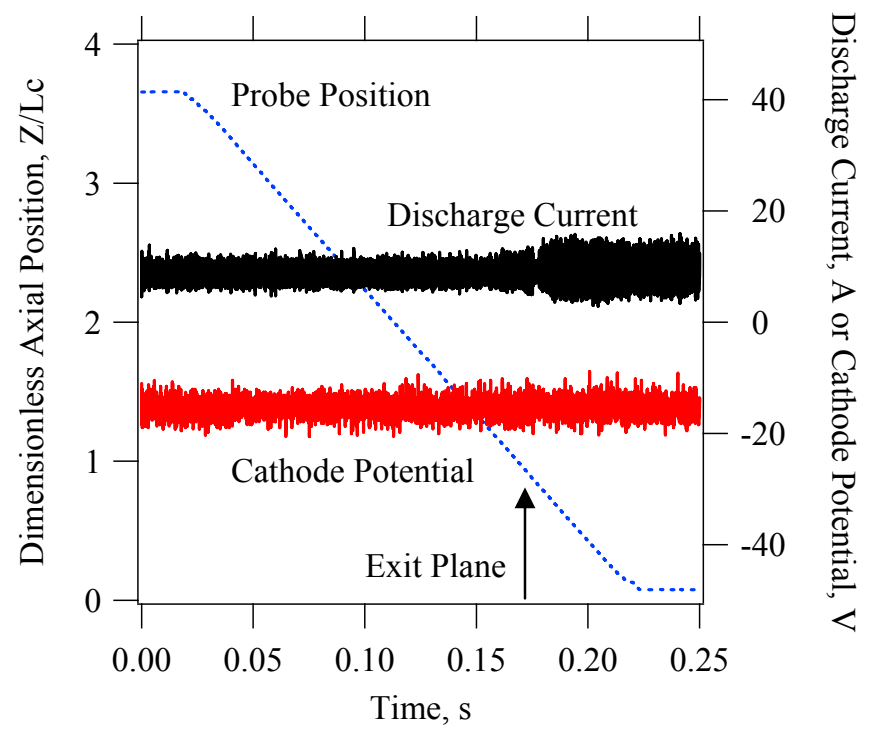

Figure 7. Probe induced perturbations of discharge current and cathode potential during probe insertion.

\section{Fluctuations of Plasma Properties}

The fluctuation of collected current due to thruster discharge oscillations is clearly seen in the raw I-V trace in Figure 8 . The probe was located approximately $360 \%$ Lc downstream from the anode for thruster operating conditions of $300 \mathrm{~V}, 10 \mathrm{mg} / \mathrm{s}$. The I-V trace is accompanied by the discharge current and cathode potential, which correlate to the fluctuation in the collected current of the I-V trace. This I-V trace can be analyzed as three distinct I$\mathrm{V}$ characteristics; the upper bound, lower bound, and smoothed characteristics. When analyzed separately, the floating potential and ion saturation remain constant, while the plasma potential and electron temperature varied by less than $2 \mathrm{~V}$, and $1 \mathrm{eV}$, respectively. 


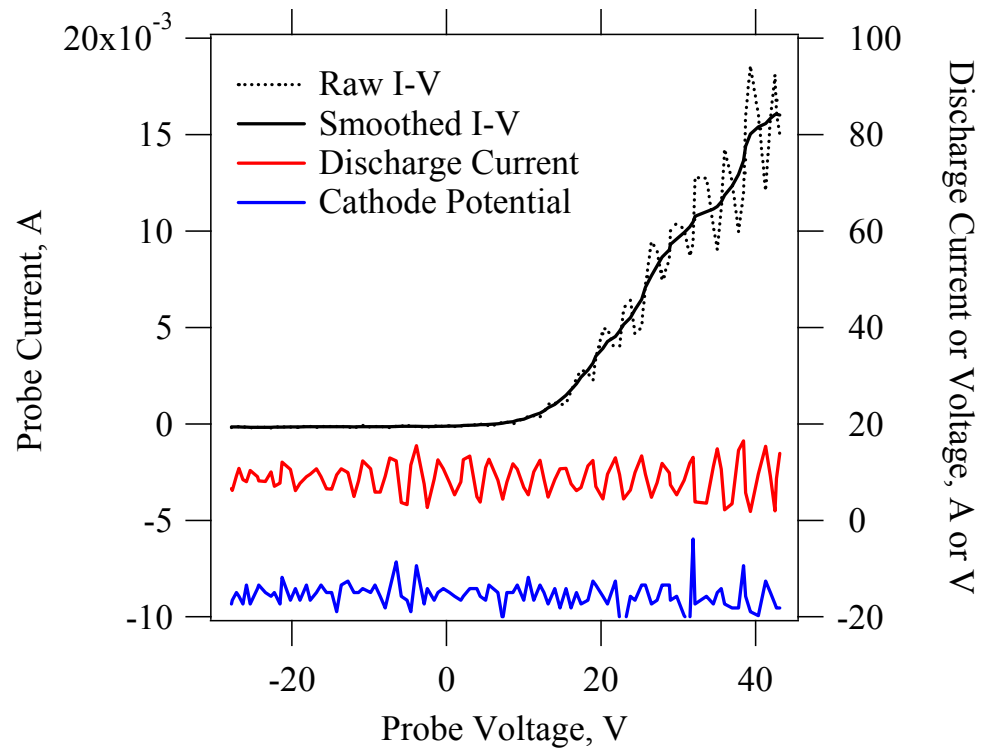

Figure 8. I-V trace, discharge current, and cathode potential $360 \%$ Lc from the anode for thruster operating at $300 \mathrm{~V}, 10 \mathrm{mg} / \mathrm{s}$.

\section{Results}

Langmuir probe measurements were taken throughout the discharge channel at a discharge voltage of $300 \mathrm{~V}$ and anode flow rates of 10,20 , and $30 \mathrm{mg} / \mathrm{s}$. Each operating condition had a cathode flow fraction of $7 \%$ and fixed magnetic field topology. The magnetic field strength was optimized at each operating condition by minimizing the discharge current while maximizing the measured thrust.

\section{A. Floating Potential}

The floating potential was similar in shape to the plasma potential and its location of maximum slope occurred $10-20 \%$ Lc upstream of the maximum slope of the plasma potential. The spatial separation of the plasma and floating potentials was consistent with the increased electron temperature inside the channel. A comparison of the floating potential on channel centerline is shown in Figure 9 for 10, 20, and $30 \mathrm{mg} / \mathrm{s}$. The profiles were similar in shape, however, the floating potential inside the channel at $30 \mathrm{mg} / \mathrm{s}$ was $10-20 \mathrm{~V}$ below the potential at 10 and 20 $\mathrm{mg} / \mathrm{s}$.

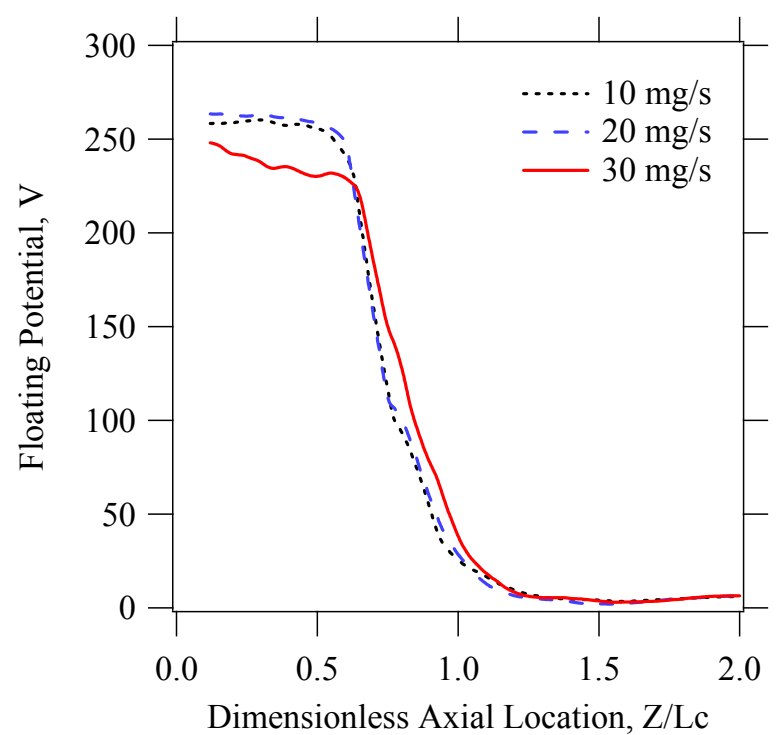

Figure 9. Comparison of floating potential on channel centerline for thruster operating conditions of $300 \mathrm{~V}$ at 10, 20, and $30 \mathrm{mg} / \mathrm{s}$. 


\section{B. Electron Temperature}

The electron temperature is shown for $300 \mathrm{~V}$ at 10,20 , and $30 \mathrm{mg} / \mathrm{s}$ in the first row of Figure 13 . The electron temperature was somewhat irregular across the channel, accounting for much of the irregularity in the ion density calculations. The electron temperature peaked at approximately 38,35 , and $25 \mathrm{eV}$ at 10,20 , and $30 \mathrm{mg} / \mathrm{s}$, respectively. The decrease in electron temperature with increased flow rate was attributed to increased neutral collisions that cool the electrons. The peak electron temperature moved downstream with each addition of anode flow rate, occurring at approximately 86,90 , and $98 \% \mathrm{Lc}$, at 10,20 , and $30 \mathrm{mg} / \mathrm{s}$, respectively.

The electron temperature from the Langmuir probe was compared to the emissive in Ref. [13], displaying excellent agreement in shape, peak location, and magnitude at $10 \mathrm{mg} / \mathrm{s}$. However, the emissive probe electron temperature did not exhibit the decreasing trend with increased flow rate, instead increasing nearly linearly from 30 to $40 \mathrm{eV}$ from 10 to $30 \mathrm{mg} / \mathrm{s}$. The emissive probe electron temperature was relatively high, and since it did not account for the effects of high-energy ions, may be less reliable, especially at higher ion densities. Further details on the emissive probe electron temperature calculation at these operating conditions can be found in Ref. [13].

A comparison of electron temperature on channel centerline is shown in Figure 10 for 10, 20, and $30 \mathrm{mg} / \mathrm{s}$. The data are somewhat irregular, but the trend of decreasing peak electron temperature and location of peak moving downstream is apparent.

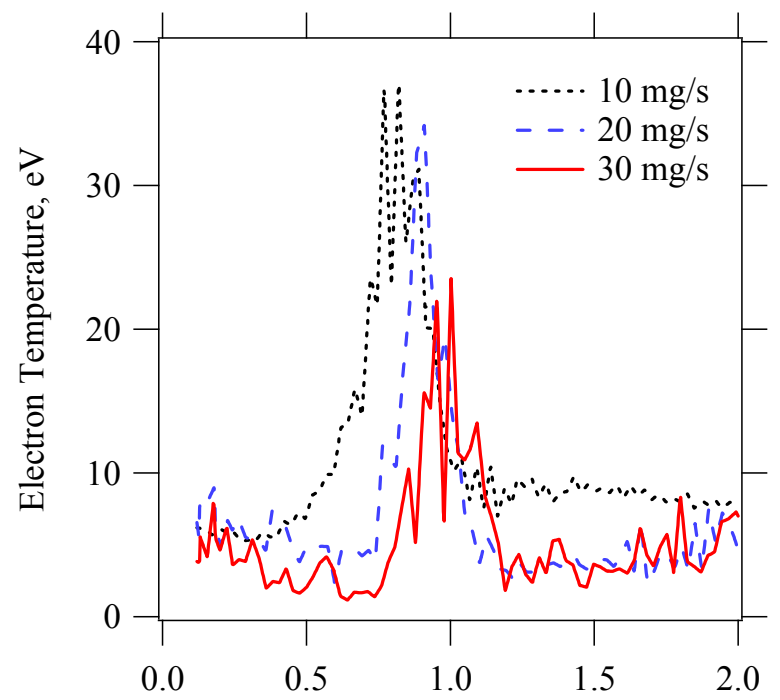

Dimensionless Axial Location, Z/Lc

Figure 10. Comparison of electron temperature calculated by the Langmuir probe on channel centerline for thruster operating conditions of $300 \mathrm{~V}$ at 10,20 , and $30 \mathrm{mg} / \mathrm{s}$.

\section{Ion Number Density: Thin Sheath vs OML}

The selection of thin sheath versus OML was somewhat subjective, and was based on the recommendation of Chen [9] that analysis techniques be chosen based on the probe radius to Debye length ratios; for ratios below three, the OML analysis is more appropriate, and for ratios above ten, the thin sheath analysis is more appropriate. The probe radius to Debye length ratios for $300 \mathrm{~V}, 10,20$, and $30 \mathrm{mg} / \mathrm{s}$ are shown in Figure 11 at all radial locations as a function of distance from the anode. At $10 \mathrm{mg} / \mathrm{s}$ the ratio ranged from 2 to 6 , indicating OML dominated probe operation. At $20 \mathrm{mg} / \mathrm{s}$ the ratio ranged from 4 to 12, indicating probe operation in a transitional regime between thin sheath and OML. At $30 \mathrm{mg} / \mathrm{s}$ the ratio ranged from 5 to 22, indicating thin sheath dominated probe operation.

The thin sheath and OML densities are shown at each operating condition in Figure 13. The OML ion number density was highly symmetric about channel centerline, peaking at 2,4 , and $9 \times 10^{18} \mathrm{~m}^{-3}$. The thin sheath density exhibited more non-uniformity throughout the domain due to the non-uniform electron temperature. The thin sheath number density peaked at 1,4 , and $15 \times 10^{18} \mathrm{~m}^{-3}$, reasonable agreement with the OML considering the $>50 \%$ estimated uncertainty for each calculation. The magnitude of the peak density at $10 \mathrm{mg} / \mathrm{s}$ appeared reasonable since the peak density of two similar size thrusters operating at $300 \mathrm{~V}, 10 \mathrm{mg} / \mathrm{s}$ was reported as $3 \times 10^{18} \mathrm{~m}^{-3}$ [2] and $1 \times 10^{18}$ $\mathrm{m}^{-3}$ [1]. In general, we expect that the ion density is directly proportional to the anode mass flow rate, so scaling based on the ion density at $10 \mathrm{mg} / \mathrm{s}$, we expected densities of $2-4$ and $3-6 \times 10^{18} \mathrm{~m}^{-3}$ at 20 and $30 \mathrm{mg} / \mathrm{s}$, respectively. The data at $20 \mathrm{mg} / \mathrm{s}$ were consistent with this relationship, however, the density at $30 \mathrm{mg} / \mathrm{s}$ was a factor of two to three greater than expected. 


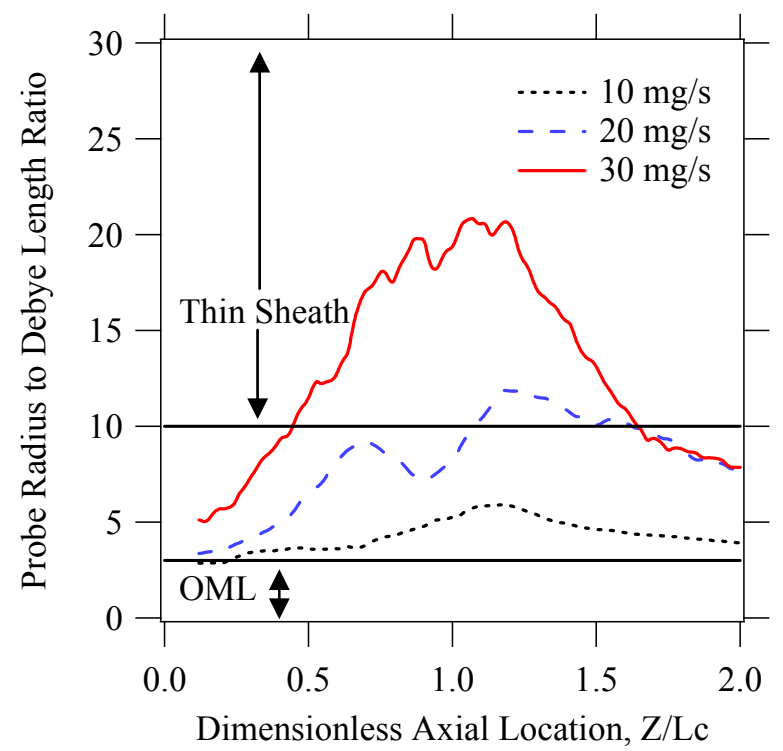

Figure 11. Probe radius to Debye length ratio at all operating conditions (smoothed for clarity).

The peak OML density locations were 86,90 , and $98 \% \mathrm{Lc}$, and the peak thin sheath density locations were at 86 , 74 , and $79 \% \mathrm{Lc}$ at 10,20 , and $30 \mathrm{mg} / \mathrm{s}$, respectively. The $10 \mathrm{mg} / \mathrm{s}$ peak location was the same for thin sheath and OML, but the peak density location for thin sheath at 20 and $30 \mathrm{mg} / \mathrm{s}$ was $7-10 \% \mathrm{Lc}$ upstream of the OML version. A comparison of OML and thin sheath ion density on channel centerline is shown in Figure 12 for 10, 20, and 30 $\mathrm{mg} / \mathrm{s}$. The data are somewhat irregular, but the trend of increasing peak ion density with increased mass flow rate is apparent for thin sheath and OML. The downstream displacement of the peak density location was also apparent for the OML density, but not as clear for the thin sheath density.

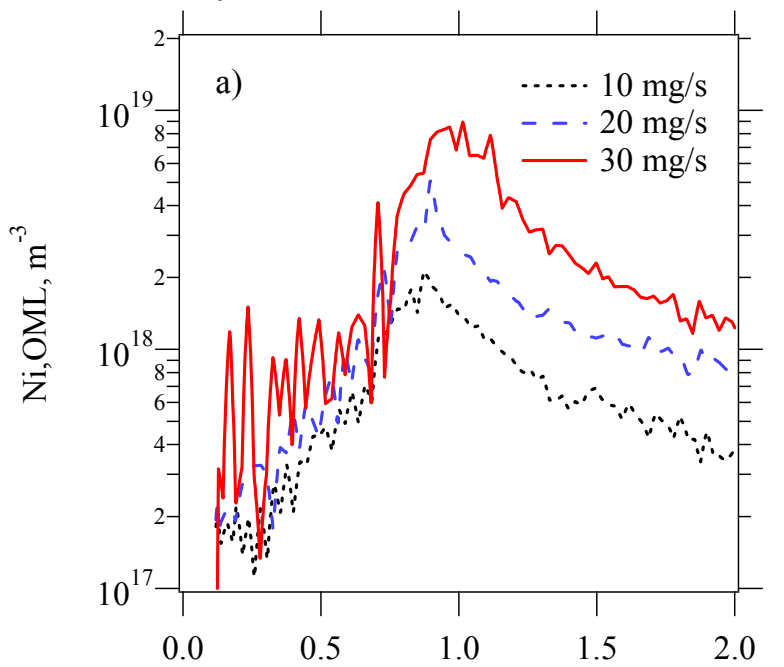

Dimensionless Axial Location, Z/Lc

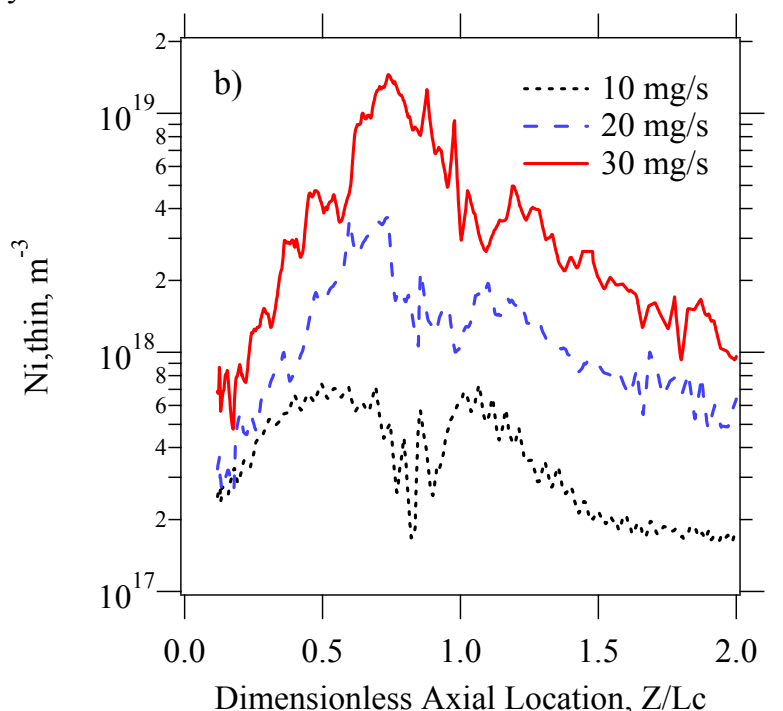

Dimensionless Axial Location, Z/Lc

Figure 12. Centerline comparison of ion number density for a) OML and b) thin sheath analysis methods.

The two ion density analysis techniques were reasonably well correlated, especially at lower flow rates. The OML density was preferred at all conditions since the location of the peak density matched well with the peak electron temperature location and the increase in the peak density magnitudes with flow rate was more consistent. Since most of the ionization was expected to occur near the peak Te location, we expected the ion density to be highest near that location. In addition, the OML density was not sensitive to the magnitude of the probe bias voltage with respect to the floating potential. Data from two probe with different probe bias pulses returned the same value 
to within $10 \%$. Conversely, the thin sheath density deviated by up to $50 \%$ for the same change in probe bias voltage.

With these observations, the OML ion density was considered the more reliable ion density measurement.

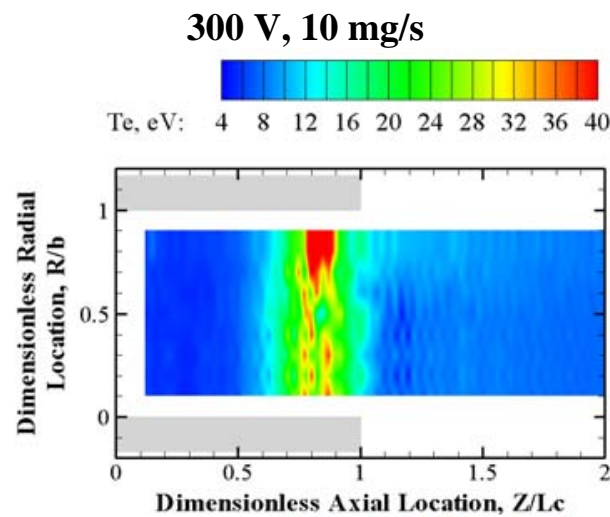

Ni,thin, $\mathrm{m}^{-3}: \quad 9 \mathrm{E}+16 \quad 3.6 \mathrm{E}+17 \quad 6.3 \mathrm{E}+17 \quad 9 \mathrm{E}+17$

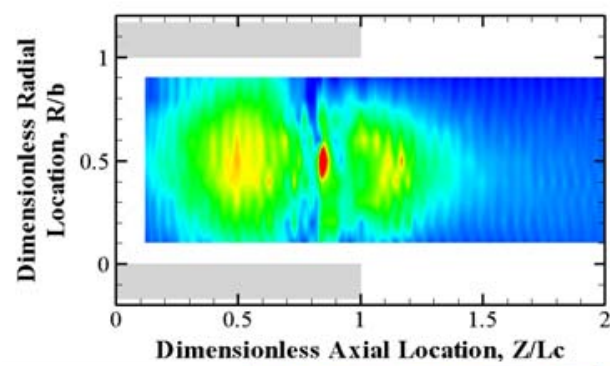

Ni,OML, $\mathrm{m}^{-3}: \quad 2 \mathrm{E}+17 \quad 8 \mathrm{E}+17 \quad 1.4 \mathrm{E}+18 \quad 2 \mathrm{E}+18$
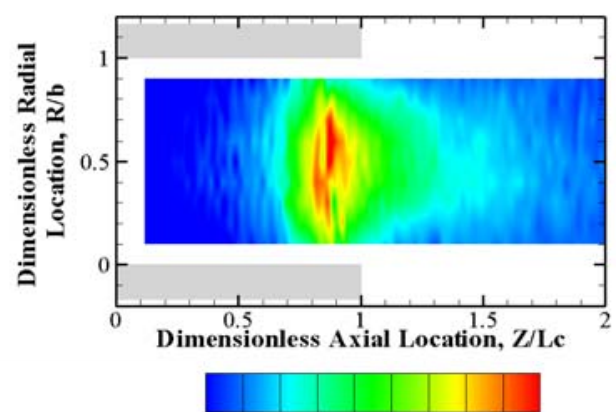

Ni,blend, $\mathrm{m}^{-3}: \quad 1.7 \mathrm{E}+17 \quad 6.8 \mathrm{E}+17 \quad 1.19 \mathrm{E}+18 \quad 1.7 \mathrm{E}+18$

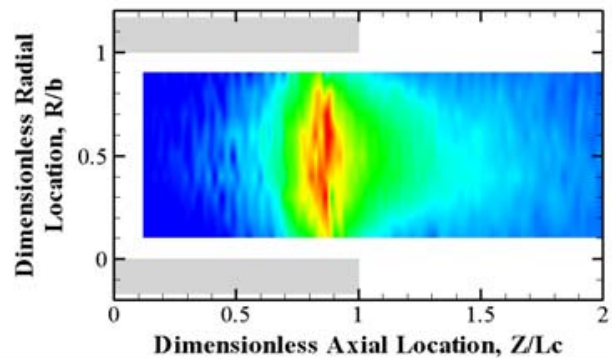

$300 \mathrm{~V}, 20 \mathrm{mg} / \mathrm{s}$

Te, eV: $\begin{array}{lllllllllll}4 & 8 & 12 & 16 & 20 & 24 & 28 & 32 & 36 & 40\end{array}$

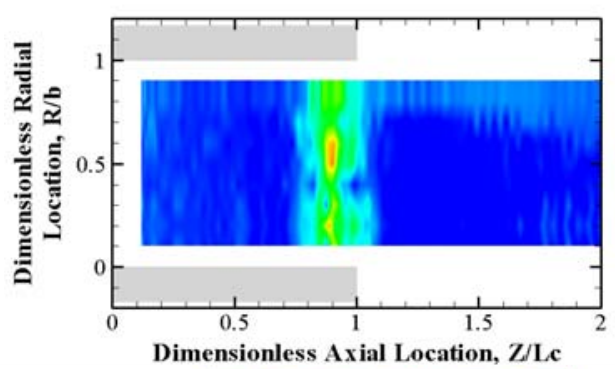

Ni,thin, $\mathrm{m}^{-3}: \quad 4 \mathrm{E}+17 \quad 1.6 \mathrm{E}+18 \quad 2.8 \mathrm{E}+18 \quad 4 \mathrm{E}+18$

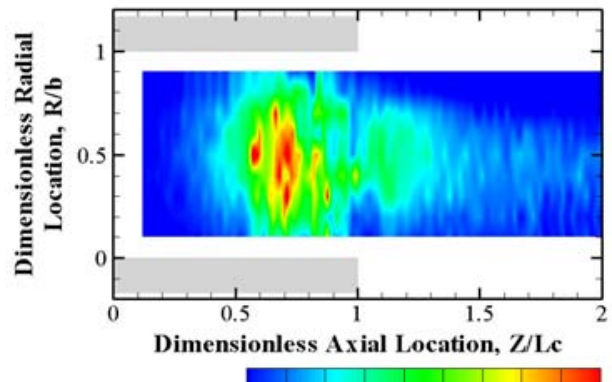

Ni,OML, $\mathrm{m}^{-3}: \quad 4 \mathrm{E}+17 \quad 1.6 \mathrm{E}+18 \quad 2.8 \mathrm{E}+18 \quad 4 \mathrm{E}+18$
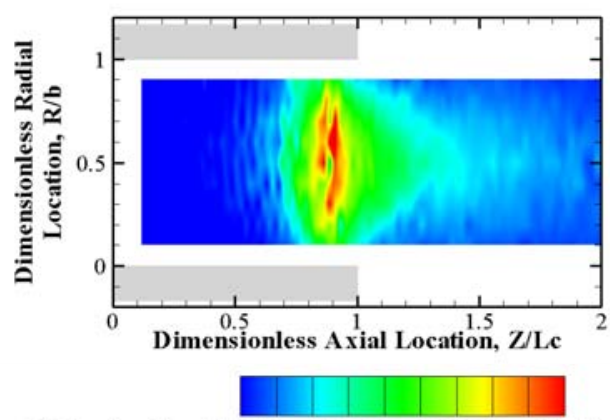

Ni,blend, $\mathrm{m}^{-3}: \quad 4 \mathrm{E}+17 \quad 1.6 \mathrm{E}+18 \quad 2.8 \mathrm{E}+18 \quad 4 \mathrm{E}+18$

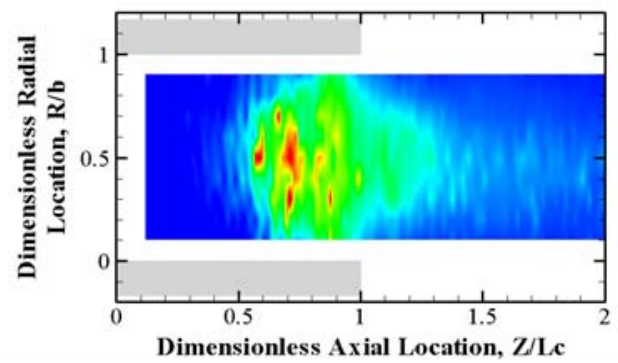

$300 \mathrm{~V}, 30 \mathrm{mg} / \mathrm{s}$

Te, eV: $\quad \begin{array}{llllllllll}4 & 8 & 12 & 16 & 20 & 24 & 28 & 32 & 36 & 40\end{array}$

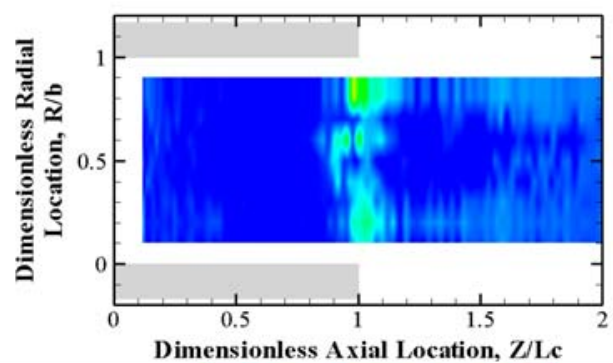

Ni,thin, $\mathrm{m}^{-3}: \quad 1.5 \mathrm{E}+18 \quad 6 \mathrm{E}+18 \quad 1.05 \mathrm{E}+19 \quad 1.5 \mathrm{E}+19$

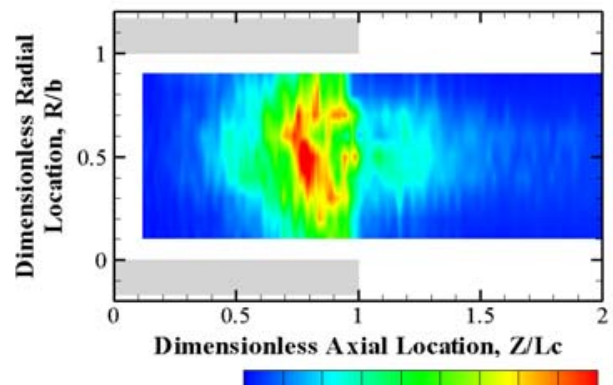

Ni,OML, $\mathrm{m}^{-3}: \quad 9 \mathrm{E}+17 \quad 3.6 \mathrm{E}+18 \quad 6.3 \mathrm{E}+18 \quad 9 \mathrm{E}+18$

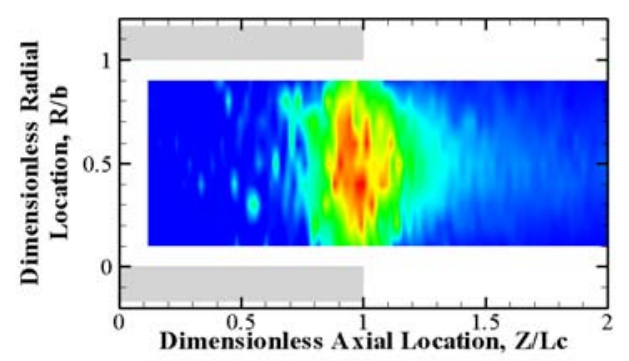

Ni,blend, $\mathrm{m}^{-3}: \quad 1.50 \mathrm{E}+165.01 \mathrm{E}+181.00 \mathrm{E}+191.50 \mathrm{E}+19$

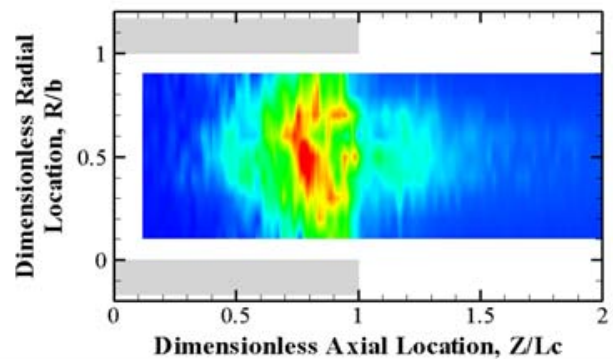

Figure 13. Major results from internal Langmuir probe measurements (contour scales for ion density are set to peak value at the maximum, and one order of magnitude lower for the minimum). 


\section{Discussion}

\section{A. Electron Temperature Cooling}

The decrease in electron temperature with increased anode flow rate observed with the Langmuir probe was likely attributed to a combination of increased electron-neutral collisions, increased production of cold electrons from ionization collisions, wall collisions, and probe secondary electron emission. The effect of electron cooling due to neutral collisions will be verified with future optical measurements of neutral temperature within the channel and in the near-field plume, combined with plasma simulations of the thruster channel and near-field plume. Whichever mechanism controlled the electron cooling with increased flow rate, further increase of the flow rate would eventually reduce the electron temperature below the electron impact ionization threshold, leading to poor thruster operation and eventually loss of plasma discharge.

Although the electron temperature from the Langmuir probe showed a convincing decreasing trend with increased flow rate, the true trend could be less abrupt due to the large uncertainty associated with the electron temperature calculation. The non-ideal structure of the I-V trace introduces some ambiguity in selecting the bounds for slope calculation. Shifting by a few volts can lead to $10-30 \%$ changes in the electron temperature. Based on several rudimentary tests of electron temperature sensitivity, the uncertainty was estimated as $\pm 30 \%$. This indicates that a portion of the electron temperature cooling could be an artifact of the analysis method, not necessarily a plasma related phenomenon.

\section{B. Ion Flux Comparison with Discharge Current}

The accuracy of the ion density was evaluated by calculating the ion flux on a downstream plane and comparing it to the estimated beam current based on $80 \%$ of the discharge current. Using the ion number density from the Langmuir probe and ion velocity derived from the plasma potential in Ref. [13], the ion flux was calculated at $150 \%$ Lc. This location was chosen to ensure that significant beam divergence or loss of main beam ions to CEX was minimized, while capturing the primary ion acceleration. The thin sheath ion flux overestimated the beam current by a factor of 1.1, 1.6, and 2.0 at 10,20, and $30 \mathrm{mg} / \mathrm{s}$, respectively, and the OML flux over predicted by 2.9, 2.3, and 2.5 at the three flow rates. These estimates values were not corrected for the missing data near the walls, an effect that would increase the calculated beam current by approximately $10 \%$.

The beam current calculated from the ion flux had a relatively large uncertainty associated with it, stemming from the uncertainty in ion density and ion velocity. The ion velocity had a relatively low uncertainty associated with it when compared to the ion density. The velocity was derived from the plasma potential, which was accurate to $5-10 \%$, and the terminal velocity was confirmed by retarding potential analyzer measurements in Ref. [13]. Therefore, any over prediction of beam current indicates that the measured ion number density was too high.

Although the OML analysis did not require the collection area to be augmented by the size of the sheath, if this correction was added, the OML over predicted beam current by $0.9,1.3$, and 1.6 at 10,20 , and $30 \mathrm{mg} / \mathrm{s}$, respectively. The significant improvement in agreement with beam current (similar to the thin sheath results) may indicate the possibility of an improved analysis technique for probes that are not completely characterized by thin sheath or OML analysis techniques.

\section{Over-prediction of Ion Number Density: General}

In general, the ion flux comparisons indicated that the ion density was over predicted by the thin sheath and OML analysis techniques, a characteristic that was expected from electrostatic probes that measure ion saturation current [14]. The ion density from a Langmuir probe $\left(\mathrm{Ni} \sim \mathrm{Isat} / \mathrm{As} / \mathrm{Te}^{1 / 2}\right)$ can also be overestimated if the calculated electron temperature is too low, sheath size is too small, or if tip effects are significant. The electron temperature outside the channel is $5-10 \mathrm{eV}$, which is within the range of expected temperatures. For the sheath size $(\sim$ few Debye length) to be too small, the electron temperature would have to be too small, or electron density too high $\left(\lambda_{\mathrm{D}^{\sim}} \sim\right.$ $\left.\left(T_{e} / n_{e}\right)^{1 / 2}\right)$. The sheath radius was 5-10 times greater than the Debye length at all operating conditions, within the range of expected sheath sizes. The correction for tip effects could be underestimated if the tip collection area is significantly larger than the probe tip area.

Although these potential sources of uncertainty in the ion density were accounted for, the impact may be underestimated using the correction methods outlined previously. Since the peak ion density location was of primary interest, uncertainty in the magnitude of the ion density were not considered detrimental to the remaining analysis. 


\section{Over-prediction of Ion Number Density: Thermionic Emission}

The intense probe heating inside the channel, can lead to thermionic emission from the collecting electrode. The temperatures necessary for thermionic emission of the tungsten electrode were likely approached at $20 \mathrm{and} 30 \mathrm{mg} / \mathrm{s}$, evidenced by the need for high-temperature materials to prevent the probe body from melting. The effects of thermionic emission can be manifested in a Langmuir probe I-V trace by a DC offset in the direction of ion saturation. This DC offset directly increases the calculated ion density. The maximum uncertainty due to thermionic emission can be bounded by using an estimate of the probe temperature and the Richardson-Dushman relation to calculate the emitted electron current. This possible offset in probe current represents a potential over prediction of ion density of $10^{16}-10^{18} \mathrm{~m}^{-3}$ from 10 to $30 \mathrm{mg} / \mathrm{s}$. The over prediction of ion current due to thermionic emission of electrons can reach $10-100 \%$ within the discharge channel where most heating is expected to occur. This analysis predicted a larger correction at higher flow rates (increased heating), consistent with the increased magnitude of over prediction of ion density (see ion flux calculations in Section IV.C.). Although probe heating was a potential source of uncertainty in the ion number density calculation, no correction was attempted, and the effect was expected to be relatively small based on the high level of agreement between the insertion and removal probe current signals. Since the primary mode of probe heating was electron impact, the effect of thermionic emission could be augmented at higher positive probe voltages that attract more electrons. This effect would cause an increased offset of the I-V curve at higher voltage, causing the electron temperature calculation to be artificially decreased. The effect would get worse at higher flow rate (higher power, more heating), leading to a systematic increase in the underprediction of electron temperature. However, the probe was not biased near the plasma potential in this study, so the collector should not see an appreciable increase in heating as the probe bias is increased. Therefore, the trend of decreasing electron temperature with increased flow rate is expected to remain valid.

\section{E. Ionization Length}

RPA [13] and E $\times \mathrm{B}$ [17] results indicated increased energy spreading with increased flow rate. Larger spreads are typically attributed to longer ionization or acceleration zones; however, the ionization length does not appear to increase significantly with higher flow rates, and the acceleration length tended to get smaller with increased flow rate [13]. The ionization length can be somewhat arbitrarily defined as the locations of $80 \%$ of the peak density. The data indicate that the ionization length was 10,8 , and $17 \% \mathrm{Lc}$ for OML and 11, 15, and $11 \% \mathrm{Lc}$ for thin sheath. The internal data do not strictly support or deny the conclusion that increased energy spread measured by the two probes at higher flow rates are related to variations in the ionization length.

\section{Conclusion}

Measurements of plasma density and electron temperature in the discharge channel and near-field plume were taken at a discharge voltage of $300 \mathrm{~V}$ and anode flow rates of 10,20 , and $30 \mathrm{mg} / \mathrm{s}$. The cathode flow fraction and magnetic field topology were held constant, and the magnetic field strength was varied to minimize discharge current while maximizing thrust. The peak density was shown to coincide with the peak Te location which were both located near the location of maximum radial magnetic field. The maximum axial electric field was typically located $7-10 \%$ Lc downstream of this location [13].

Over the wide range of discharge powers $(3-10 \mathrm{~kW})$, the results showed that the location of the peak ion density, electron temperature, and axial electric field all moved downstream 3-5\% Lc for each $10 \mathrm{mg} / \mathrm{s}$ increase in anode flow rate. Significant ion density was not measured from 0 to $48 \% \mathrm{Lc}$ from the anode, and the ionization length remained relatively constant at each operating condition.

The peak electron temperature was found to decrease with increased flow rate, peaking at approximately 40, 30, and $20 \mathrm{eV}$ at 10,20 , and $30 \mathrm{mg} / \mathrm{s}$. The trend was attributed to increased electron loss mechanisms including increased electron-neutral collisions and wall collisions, although the non-Maxwellian EEDF may play a large role in obscuring this measured trend.

The OML analysis method was chosen over the thin sheath analysis due to better matching of location with peak Te and better consistency with calculated beam current. The OML ion density produced calculated ion beam currents (ion flux) that were 2.9, 2.3, and 2.5 times greater than the $0.8 \mathrm{I}_{\mathrm{D}}$. Several mechanisms for the over prediction of ion density were discussed, providing future avenues to increase the fidelity of the OML density calculation.

\section{Acknowledgments}

The authors would like to thank Mr. Michael McDonald and Mr. Rohit Shastry for their assistance with the experimental setup and data acquisition. Mr. Terry Larrow provided invaluable help in producing several prototype 
probe components. We would also like to recognize Dr. Jesse Linnell for his many fruitful discussions and suggestions. The first author has been supported throughout his graduate studies by the NASA Michigan Space Grant Consortium Fellowship, NASA Harriett Jenkins Pre-doctoral Fellowship Program, and the University of

Michigan Rackham Merit Fellowship. The authors would like to acknowledge and thank the Air Force Office of Scientific Research (AFOSR) for funding this research. Dr. Mitat Birkan is the Project Manager for Grant FA955006-1-0105.

\section{References}

[1] Haas, J. M., "Low-Perturbation Interrogation of the Internal and near-Field Plasma Structure of a Hall Thruster Using a High-Speed Probe Positioning System," Ph.D. Dissertation, Dept. of Aerospace Engineering, University of Michigan, 2001.

[2] Linnell, J. A., "An Evaluation of Krypton Propellant in Hall Thrusters," Ph.D. Dissertation, Dept. of Aerospace Engineering, University of Michigan, Ann Arbor, 2007.

[3] Haas, J. M., Hofer, R. R., Brown, D. L., Reid, B. M. and Gallimore, A. D., "Design of the \#\# Hall Thruster for High Thrust/Power Investigation," Presented at the 54th JANNAF Propulsion Meeting, Denver, CO, May 14-17, 2007.

[4] Reid, B. M., Gallimore, A. D., Hofer, R. R., Li, Y. and Haas, J. M., "Anode Design and Verification for the \#\# Hall Thruster," Presented at the 54th JANNAF Propulsion Meeting, Denver, CO, May 14-17, 2007.

[5] Hofer, R. R., Goebel, D. M. and Watkins, R. M., "Compact LaB6 Hollow Cathode for the \#\# Hall Thruster," Presented at the 54th JANNAF Propulsion Meeting, Denver, CO, May 14-17, 2007.

[6] Brown, D. L., Reid, B. M., Gallimore, A. D., Hofer, R. R., Haas, J. M., et al., "Performance Characterization and Design Verification of the \#\# Laboratory Model Hall Thruster," Presented at the 54th JANNAF Propulsion Meeting, Denver, CO, May 14-17, 2007.

[7] Dymond, J. H. and Smith, E. B., The Virial Coefficients of Pure Gases and Mixtures, a Critical Compilation, Oxford University Press, New York, 1980.

[8] Haas, J. M., Gallimore, A. D., McFall, K. and Spanjers, G., "Development of a High-Speed, Reciprocating Electrostatic Probe System for Hall Thruster Interrogation," Review of Scientific Instruments, 71, 11, 4131-4138, 2000.

[9] Chen, F. F. "Electric Probes." Plasma Diagnostic Techniques, R. H. Huddlestone and S. L. Leonard, eds., Academic Press, New York. 1965.

[10] Hershkowitz, N. "How Langmuir Probes Work." Plasma Diagnostics, O. Auciello and D. L. Flamm, eds., Academic Press, Inc., Boston, 113-184. 1989.

[11] Cherrington, B. E., "The Use of Electrostatic Probes for Plasma Diagnostics - a Review," Plasma Chemistry and Plasma Processing, 2, 2, 113-140, 1982.

[12] Aikawa, H., "The Measurement of the Anisotropy of Electron Distribution Function of a Magnetized Plasma," Journal of the Physical Society of Japan, 40, 6, 1741-1749, 1976.

[13] Reid, B. M. and Gallimore, A. D., "Plasma Potential Measurements in the Discharge Channel of a 6-kW Hall Thruster," 44th AIAA/ASME/SAE/ASEE Joint Propulsion Conference, AIAA-2008-5185, Hartford, CT, Jul. 20-23, 2008.

[14] Lieberman, M. A. and Lichtenberg, A. J., Principles of Plasma Discharges and Materials Processing, John Wiley \& Sons, Inc., New York, 1994.

[15] Laframboise, J. G., "Theory of Spherical and Cylindrical Langmuir Probes in a Collisionless, Maxwellian Plasma at Rest," UTIAS Report No. 100, Institute for Aerospace Studies, University of Toronto, Toronto, Canada, June 1966.

[16] Raitses, Y., Staack, D., Smirnov, A. and Fisch, N. J., "Space Charge Saturated Sheath Regime and Electron Temperature Saturation in Hall Thrusters," Physics of Plasmas, 12, 073507, 2005.

[17] Reid, B. M., Shastry, R., Gallimore, A. D. and Hofer, R. R., "Angularly-Resolved ExB Probe Spectra in the Plume of a 6-kW Hall Thruster," 44th AIAA/ASME/SAE/ASEE Joint Propulsion Conference, AIAA-2008-5287, Hartford, CT, Jul. 20-23, 2008. 